\title{
The Relationship Between Individual Stock Trading And Returns: The Case Of An Emerging Market
}

Abdollah Khani, University of Isfahan, Iran Ali Saeedi, Taylor's University, Malaysia

Asieh Khadem Khorasani, University of Isfahan, Iran

\begin{abstract}
This research investigates the relationship between stock trading of individual investors and returns in short horizon in an emerging market. The results indicate that the individuals would like to invest in stocks after declining in the preceding month prices and they would like to sell after increasing in prices. Moreover, we find that there are positive abnormal returns in the month after high buying by individuals and there are negative abnormal returns following high individuals selling. The result is consistent with the literature that the individuals play roles of liquidity providers because they can meet the institutional need of immediacy.
\end{abstract}

Keywords: Individual Investors; Individual Stock Trading; Behavioral Finance; Emerging Markets

\section{INTRODUCTION}

C n 1996, household investments comprised almost 47 percent of stock investment in the United States (Barber and Odeon, 2000). This issue incites Barber and Odeon (2000) and other researchers to study individual investor behavior in the US equity market. But, in the course of the 2020s decade, the developed countries investors become older, they reduce their equity holdings and they are likely to shift from buying stocks to selling their equity and holding finance retirement (Liu and Spiegel, 2011). Meanwhile, emerging markets are growing nearly four times quickly than in developed economies, household financial assets portion in the emerging markets will increase from nearly $15 \%$ at 2010 to $45 \%$ at 20201 . Unfortunately, there is little research on the individual investors in the emerging equity markets, despite their increasing ownership of equities. Therefore, this paper attempts to provide evidence about performance of trading of the individual investors in Tehran Stock Exchange (TSE). Iran is a developing country in Middle East and North Africa (MENA) (Billmeier and Isabella, 2009) and it is a member of the Next Eleven (N-11) (O’Neill et al., 2005).

Studies indicate that individuals and institutions have different behaviors trading in financial market. Some of the studies indicate irrational behavior, such as fad behavior. However, the other studies indicate rational behavior. Rationality or irrationality depends on the theory and the applied research method. The disposition effect of the Investors is so that they are reluctant to realize losses. On the other hand, they prefer to hold losing investments for a longer time compare to winning investments (Shefrin and Statman, 1985). They are Anti-momentum or contrarian; traders buy (sale) tomorrow in response to an increase (decrease) in today's price (Griffin et al., 2003). The individual investors hold under-diversified portfolios (Polkovnichenko, 2005; Goetzmann and Kumar, 2001; Lakonishok and Smidt, 1986). Overconfidence causes the individual investors to overestimate the accuracy of their private information signals (Odean, 1998; Daniel et al., 1998; Barber and Odean, 2000; DØskeland and Hvide, 2011). Regarding investors' responses to past prices, trading volume (turnover) for the price decreasing shares (losers) is higher than for price increasing shares (winners) (Polkovnichenko, 2005; Goetzmann and Kumar, 2001). The individuals, one week experience sizeable return reversals the next week (Lehmann, 1990; Jegadeesh, 1990). This reversal can be due to either illiquidity or overreaction (Kaniel et al., 2008). However, the investors may show a strong priority for realization of winners sooner than losers by considering the following rational behavior of the

1- McKinsey Global Institute 
individual investors (Odean, 1998): attempts for rebalancing of their portfolios; expecting that performance of the losers is better than the winners in the future (Lakonishok and Smidt, 1986); investors are sensitive to higher trading costs when share prices are lower (Harris, 1988).

Following Kaniel et al. (2008), this paper examines the aforementioned theories, specifically the contrarian trading and the reversal returns. It examines the relationship between the individual investors' buying and selling and both preceding and succeeding returns in TSE. In the other words, the paper studies the relationship between the individual high net buying and selling of a stock with the past returns of the stock. As well, it investigates the ability of individuals' high net trading for future returns predictions. The research findings indicate that the individual investors prefer to buy (sell) after decreasing (increasing) in stock prices, and also the contrarian tendency of individual investors causes them to provide liquidity to those investors (e.g. institutional investors) who need immediacy (Grossman and Miller, 1988; Kaniel et al., 2008).

This paper contributes to the literature on the individual investors' behavior in buying and selling stocks, especially the literature which explains that individuals prefer to be contrarian and provide liquidity to institutions. Our analysis relating to individual investors' stock trading in the companies listed on TSE indicates two significant results. Firstly, it is finds that the relationship between net individual buying and selling and future returns in shorthorizon is negative. In the other words, prices increase in the month after individual high buying and decrease following individual high selling. This result is contrary to that of Kaniel et al. (2008). Second, we conclude that the net trading of individuals cannot be covered by the volume of trading or the return reversal.

The remainder of the research paper is formed as follows. The next section illustrates the sample and the data set. Section 3 exhibits investigation of the relationship between the net individual trading and stock returns. As well, it covers the investigation of the predictive ability of the short-horizon return of the net trading by the individual investors is performed in section. Section 4 explains the results.

\section{DATA AND SAMPLE}

This paper uses the data regarding the buying and selling the stocks by individual investors obtained from the Tehran Stock Exchange Database (TSED). The gathered data comprises a two-year period of the daily buying and selling volume of executed individual investor orders for the stocks listed on TSE. The research sample consists of 77 companies which their common stocks traded on the TSE over March 21, 2010 to March 20, 2012 ${ }^{2}$. Table 1 presents a summary of the statistics for the whole sample, as well, for three different sized groups.

Table 1: Summary Statistics of Sample Stocks

\begin{tabular}{lcccc}
\hline & & AveCap & AvePrc & $\begin{array}{c}\text { AveTurn } \\
\text { (in \%) }\end{array}$ \\
\hline All stocks & Mean & 2562.99 & (in billion Rls.) & 0.1201 \\
& Median & 636.76 & 5013.42 & 0.0653 \\
Small stocks & Mean & 194.54 & 3640.97 & 0.1870 \\
& Median & 162.69 & 3664.54 & 0.1325 \\
Mid-cap stocks & Mean & 762.90 & 2826.78 & 0.0906 \\
& Median & 792.87 & 4425.40 & 0.0433 \\
Large stocks & Mean & 7347.32 & 3538.92 & 0.0617 \\
& Median & 3827.6 & 7319.24 & 0.0399 \\
\hline
\end{tabular}

The monthly Rials ${ }^{3}$ average market capitalization (Avgcap) of the individual investors is 2,562,990 million Rials and it varies between 194,540 million Rials in small stocks to 7,347,320 million Rials in large stocks. FollowingKaniel et al. (2008), we calculate time-series measures for each of the stocks as follows: AvgCap is the average monthly market capitalization over the research period; AvgPrc is the average daily closing price; AvgTurn is the average weekly turnover (number of traded stocks divided by the number of outstanding stocks). Using market capitalization, the stocks are classified into 10 deciles. Then, those are formed in three size groups as follows: small stocks (deciles 1,2,3, and 4), mid-cap stocks (deciles 5, 6, and 7), and large stocks (deciles 8, 9, and 10). The cross-section mean and median of the aforementioned measures are presented for the entire sample and separately for each of the three groups.

\footnotetext{
${ }^{2}$-Beginning day of the Iranian calendar is at March 21.

3 - Iranian currency is Rial.
} 
To measuring daily net individual trading, the value of stocks sold by the individual investors is deducted from the value of stocks bought by them. And then, we standardize this measure by using daily mean Rials amount in preceding year. The NIT for stock i on day $t$ is as follows (Kaniel et al., 2008):

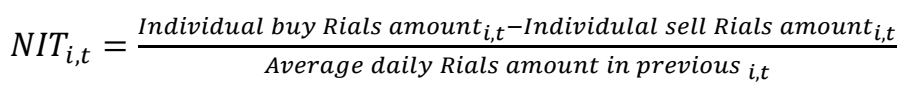

We use the average daily Rials of stock's trading volume for the year ending on day t-1 as the denominator. Table 2 reports a summary statistics of the weekly NIT measure. Panel A shows a cross-section distribution of stocks' average of NIT. As it is indicated the time-series mean for NIT during the years 2010-2012 is negative, which means number of stocks sold by the individual investors are more than stocks bought by them.

Table 2: Summary Statistics of Individuals' Trading Instabilities

\begin{tabular}{|c|c|c|c|c|c|}
\hline \multicolumn{6}{|c|}{ Panel A: Cross-Section Distribution of Stocks' Average NIT } \\
\hline Size Quintiles & Mean & Std. Dev. & Min & Max & Median \\
\hline Q1 (small stocks) & -0.2050 & 0.1878 & -0.6027 & 0.0987 & -0.1832 \\
\hline Q2 & -0.1127 & 0.1150 & -0.3582 & 0.0341 & -0.1083 \\
\hline Q3 & -0.1679 & 0.1193 & -0.3817 & 0.0218 & -0.1557 \\
\hline Q4 & -0.1601 & 0.1258 & -0.4439 & 0.0439 & -0.1503 \\
\hline Q5 (large stocks) & -0.2039 & 0.1024 & -0.5158 & -0.1151 & -0.1787 \\
\hline \multicolumn{6}{|c|}{ Panel B: Cross-Section Distribution of Stocks' Standard Deviation of NIT } \\
\hline Size Quintiles & Mean & Std. Dev. & Min & Max & Median \\
\hline Q1 (small stocks) & 0.4917 & 0.2122 & 0.1761 & 0.8127 & 0.4542 \\
\hline Q2 & 0.4513 & 0.1444 & 0.2267 & 0.7329 & 0.4850 \\
\hline Q3 & 0.4475 & 0.1907 & 0.1663 & 0.9969 & 0.4351 \\
\hline Q4 & 0.4283 & 0.1817 & 0.0987 & 0.7587 & 0.4288 \\
\hline Q5 (large stocks) & 0.3428 & 0.1016 & 0.1511 & 0.5131 & 0.3470 \\
\hline \multicolumn{6}{|c|}{ Panel C: Summary Statistics of NIT in High Individual Buying or Selling Portfolios } \\
\hline Portfolio & & & Mean & Std. Dev. & Median \\
\hline \multirow{4}{*}{\multicolumn{2}{|c|}{ High individual selling portfolio (decile 1) }} & All stocks & -0.9666 & 1.5817 & -0.5115 \\
\hline & & Small stocks & -1.0215 & 1.7373 & -0.5057 \\
\hline & & Mid-cap stocks & -0.9703 & 1.4747 & 0.5144 \\
\hline & & Large stocks & -0.8889 & 1.4692 & -0.5221 \\
\hline \multirow{4}{*}{\multicolumn{2}{|c|}{ High individual buying portfolio (decile 10 ) }} & All stocks & 0.2165 & 0.5361 & 0.0074 \\
\hline & & Small stocks & 0.1891 & 0.4866 & 0.0000 \\
\hline & & Mid-cap stocks & 0.2671 & 0.5860 & 0.0404 \\
\hline & & Large stocks & 0.2044 & 0.5467 & 0.0258 \\
\hline
\end{tabular}

The research sample includes common stocks traded on the TSE during March 21, 2010 to March 20, 2012 which are recorded in the TSED. NIT $t$ for a stock on week $\mathrm{t}$ is defined as the Rials amount bought by individual investors minus those sold by individual investors, divided by a moving average of previous 1-year average Rials amount. Panel A of the Table 2 presents the time-series means of each stock's NIT during the research sample period. The stocks are classified into five size quintiles in accordance with average stock market capitalization, and cross-section summary statistics of the stocks' NIT for each of the quintiles presented. We find that the time-series mean of NIT during the years 2010 to 2012 is negative which indicates that stocks sold by individual investors are larger than stocks bought. Panel B shows the time-series standard deviation of each stock's NIT during research sample period and cross-section summary statistics for the five size quintiles. Panel B shows that the stock NIT's time-series standard deviation is larger, its average size is twice the mean for small stocks or the mean is 1.5 times for large stocks. It indicates that NIT may be quite small, but we may observe a rather large NIT. Panel C exhibits the summary statistics of NIT in weekly of stocks portfolios with high individual investors buying or selling. For each week, we use preceding 9 weeks to create deciles of NIT. Each stock is placed into 1 of 10 deciles in accordance with current week value of the NIT in respect to its value in the preceding 9 weeks. Decile 1 encompasses the stocks that have the largest individual high selling (negative NIT) although decile 10 contains the stocks that have the largest individual high buying (positive NIT). We compute the average stocks NIT in each portfolio. Then, we provide time-series summary statistics of the average NIT in each of the deciles for the whole sample and also for the three sized groups. The formation of the portfolios is similar to the method employed by Kaniel et al. (2008).

Panel B of Table 2 indicates that the time-series standard deviation for a NIT is large, and it is approximately twice the mean. It is implies that however NIT is small, we can observe large NIT. Panel A and B show that the instability extent of individual trading fluctuates overtime. As we can observe for most weeks a typical 
individual investor rebalances a few of his or her investments in each stock which doesn't have a robust, predominant direction. Because the objective of this paper is to search for dynamic patterns in which there are relationship between the buying or selling preferences of this aggregate individual investor and the returns of particular stocks, these type of patterns can be find through focusing on weeks when there are high buying or selling stocks. Therefore, following Kaniel et al. (2008) we form portfolios of stocks for each week that experience more high trading by individual investors, and then examine the patterns of returns around these events.

Table 3 indicates the cumulative market-adjusted returns before and following the individual high buying or selling. Our emphasis is on the pattern related with the individual high selling and buying portfolios, deciles 1 and 10, respectively. AS Kaniel et al. (2008) by emphasis on the short-horizon dynamics, we calculate market-adjusted cumulative returns for $20,15,10$, and 5 days before the first day and after the last day of the high individual buying and selling week. The mean of time-series and t-statistics for the cumulative return measures are provided in the table. We used the Newey-West correction to calculate the t-statistics due to possibility of serial correlation of the errors caused by overlapping periods. The first line of Table 3 indicates that individual high selling (decile 1) takes place because of increase in stock prices. The mean abnormal return in the 15 days before the week of selling is $0.31 \%$, and it is $0.28 \%$ in the 5 days before the week of selling. All of the returns are statistically significant. The last line of Table 3 indicates that the abnormal return in 20 days before individual high buying is $-0.13 \%$, which is statistically significant. The table as well indicates that there are positive abnormal returns after those weeks reporting individual high buying or selling. 


\begin{tabular}{|c|c|c|c|c|c|c|c|c|c|c|}
\hline Portfolio & & $K=-20$ & $K=-15$ & $K=-10$ & $K=-5$ & $\mathrm{~K}=\mathbf{0}$ & $K=+5$ & $K=+10$ & $K=+15$ & $K=+20$ \\
\hline $\begin{array}{l}\text { Individual High Selling } \\
\text { (decile 1) }\end{array}$ & $\begin{array}{c}\text { Mean } \\
\text { t-statistics }\end{array}$ & $\begin{array}{l}0.001978^{* *} \\
(2.90)\end{array}$ & $\begin{array}{c}0.003088^{* *} \\
(6.32)\end{array}$ & $\begin{array}{c}0.003067^{* *} \\
(5.37)\end{array}$ & $\begin{array}{l}0.002800^{* *} \\
(5.41)\end{array}$ & $\begin{array}{l}0.008528^{* *} \\
(5.81)\end{array}$ & $\begin{array}{c}-0.000891 * * \\
(-2.06)\end{array}$ & $\begin{array}{c}-0.000921 * * \\
(-2.41)\end{array}$ & $\begin{array}{c}-0.000962 * * \\
(-2.44)\end{array}$ & $\begin{array}{c}-0.000685 * * \\
(-2.33)\end{array}$ \\
\hline $\begin{array}{l}\text { Individual High Buying } \\
\text { (decile 10) }\end{array}$ & $\begin{array}{c}\text { Mean } \\
\text { t-statistics }\end{array}$ & $\begin{array}{c}-0.001298 * * \\
(-2.57)\end{array}$ & $\begin{array}{c}-0.001280 * * \\
(-2.32)\end{array}$ & $\begin{array}{c}-0.001247 * * \\
(-2.05)\end{array}$ & $\begin{array}{c}-0.001187 * * \\
(-2.02)\end{array}$ & $\begin{array}{c}-0.001986 * * \\
(-2.10)\end{array}$ & $\begin{array}{c}0.000934 * * \\
(2.10)\end{array}$ & $\begin{array}{c}0.000998 * * \\
(2.07)\end{array}$ & $\begin{array}{c}0.001014 * * \\
(2.06)\end{array}$ & $\begin{array}{l}0.001031 * * \\
(2.06)\end{array}$ \\
\hline
\end{tabular}

This table provides market-adjusted cumulative returns analysis around stock trading by individual investors. The NIT is employed for the analysis. For every week, each stock is placed into the portfolios of decile 1 or 10, which is organized by comparing the stock's NIT measure in that week to the stock's NIT measures of the same stock in the preceding 9 weeks. If the stock's NIT measure for the week is more negative than the stock's NIT measures in the preceding 9 weeks, that stock is placed into decile 1 , which means most individual high selling. If the stock's NIT measure for the week is more positive than the stock's NIT measures in the preceding 9 weeks, then that stock is placed into decile 10 , which means most individual high buying. $\mathrm{k}$ is the number of days before or after the each week portfolio. For each stock in the portfolio, eight cumulative return measures are calculated: $C R(t-k, t-1)$, where $k \in\{20,15,10,5\}$ days and $\mathrm{t}$ is the first day of portfolio forming week, and $C R(t+1, t+k)$, where $k \in\{5,10,15,20\}$ days and $\mathrm{t}$ is the last day of the portfolio forming week. For return adjustment, we subtract the market return from the return on each portfolio. For this purpose, equal-weighted portfolio of the entire sample is used. $* *$ indicates significant at $5 \%$ level. 
The decile 10 portfolio reports market-adjusted returns of $0.09 \%$ in the week following individual high buying and it presents market-adjusted returns $0.10 \%$ in the 20 days. These returns are statistically significant. We report smaller size for abnormal return following high individual selling (-0.07\% after 20 days). In addition, it is worth mentioning that abnormal returns show opposite signs during the high selling and buying by individual investors.

\section{PREDICTABILITY OF RETURNS}

In this section, we investigate the predictability of short-horizon return in the Tehran Stock Exchange (TSE). For this purpose we consider two sorts of findings in the extant literature. The first one is regarding the findings of Jegadeesh (1990) and Lehmann (1990) about short-horizon return reversals. If high individual buying goes after a period of negative returns and high individual selling goes after a period of positive returns, it may be that the short-horizon produces abnormal returns. Like Kaniel et al. (2008) we indicate that individual high trading imbalances may reflect the return reversals as Jegadeesh (1990) and Lehmann (1990). The second is considering the Gervais et al. (2001). They indicate that predicted returns increases after trading volume increments.

\subsection{Reversals of Return in Short-Term}

To examine the short-term return predictability, we create 25 portfolios by placing stocks into five quintiles on the basis of their returns in each week and five quintiles based on their NIT decile ranking for the week. Then, for each of the portfolios we calculate market-adjusted return for the subsequent week. Panel A of Table 4 shows the weekly time-series averages of the market-adjusted returns for the all of the portfolios. It is reporting that there is no evidence of return reversal in the research sample when it is conditioned on Net Individual Trading (NIT). This result is similar to that of Kaniel et al. (2008). The last two columns of the table show the payoffs for a trading policy of buying quintile 5 and selling quintile 1 . Therefore on the base of return reversal strategy, we expect that individual investors buy the last week's portfolio with most negative return and he or she sells last week's portfolio with most positive return may be generate profits, the payoffs reported in the column Q5-Q1 should be negative and significant (Kaniel et al., 2008).

Panel A of Table 4 as well presents the market-adjusted return in each column of the table turns into more positive as we move from the stocks sold by individual investors in the preceding week to those stocks that individuals bought (positive moving pattern). The last two rows in the Panel A show the payoffs to buying a portfolio that in the preceding week (NIT quintile 5) has an high individual buying and selling portfolio that has high individual selling (NIT quintile 1) in each of return quintiles. The portfolios indicate significant positive payoffs which range from $0.4348 \%$ to $0.7107 \%$. The result can implicitly indicate information content of the individual trading imbalance.

In Panel B of Table 4 shows a comparable analysis except placing stocks in portfolios based on previous turnover (instead of previous returns) and past NIT. We construct 25 portfolios comparable to Panel A. The last two columns in the Panel B show the payoff to the buying turnover (quintile 5) and selling turnover (quintile 1) strategies. The portfolios indicate significant positive payoffs which range from $0.3163 \%$ to $1.3248 \%$. The result can implicitly indicate information content of the individual trading imbalance.

\subsection{Trading Volume, NIT and Future Returns}

As it is mentioned above, we consider the Gervais et al. (2001) that indicate predicted returns increases follow trading volume increments. It is because of net individual trading correlation with volume. In order to investigate whether the relationship between NIT and return is volume independent we do the same analysis by placing the stocks into five NIT quintiles and five turnover quintiles. It is followed Gervais et al. (2001) and Kaniel et al. (2008) method to assign a stock to a turnover quintile in a given week. This method is similar to the assignment of stocks into NIT quintiles. In other words, turnover of a stock in a week is linked with the turnover of that stock in the preceding 9 weeks. 
Table 4: Return Predictability: Portfolio Sorting Approach

\begin{tabular}{|c|c|c|c|c|c|c|c|}
\hline \multicolumn{8}{|c|}{ Panel A: Weekly Return Predictability Using Past Return and NIT } \\
\hline \multicolumn{8}{|c|}{ Return $(t)$} \\
\hline NIT (t) & Q1(<0) & Q2 & Q3 & Q4 & Q5(>0) & $\overline{Q 5-Q 1}$ & t-statistics \\
\hline $\mathrm{Q} 1(<0)$ & -0.003101 & -0.003012 & -0.003180 & -0.001039 & -0.000207 & 0.002894 & $(1.59)$ \\
\hline Q2 & -0.002924 & -0.000754 & -0.000603 & -0.002416 & -0.005603 & -0.002678 & $(-0.94)$ \\
\hline Q3 & -0.001811 & -0.001209 & -0.002506 & -0.000221 & -0.004108 & -0.002296 & $(-1.03)$ \\
\hline Q4 & 0.003006 & -0.000896 & -0.002715 & 0.003222 & 0.000020 & -0.002986 & $(-1.54)$ \\
\hline $\mathrm{Q} 5(>0)$ & 0.004006 & 0.002839 & 0.003089 & 0.003309 & 0.006106 & 0.002100 & $(0.67)$ \\
\hline Q5-Q1 & $0.007107^{* *}$ & $0.005852^{* *}$ & $0.006269^{* *}$ & $0.004348^{*}$ & $0.006313^{* *}$ & & \\
\hline t-statistics & $(3.42)$ & $(2.04)$ & $(2.80)$ & $(1.87)$ & $(2.14)$ & & \\
\hline \multicolumn{8}{|c|}{ Panel B: Weekly Return Predictability Using Previous Turnover and NIT } \\
\hline \multicolumn{8}{|c|}{ Turnover(t) } \\
\hline NIT (t) & $\mathbf{Q 1}(<0)$ & Q2 & Q3 & Q4 & Q5(high) & Q5-Q1 & t-statistics \\
\hline $\mathrm{Q} 1(<0)$ & -0.013039 & -0.00211 & -0.000728 & -0.001334 & 0.000966 & $0.014005^{* *}$ & $(3.66)$ \\
\hline Q2 & -0.007856 & -0.001328 & -0.001369 & -0.000395 & 0.002542 & $0.010398^{* * *}$ & $(2.63)$ \\
\hline Q3 & -0.004402 & -0.001727 & -0.000105 & 0.000067 & 0.003473 & $0.007875^{* * *}$ & (2.37) \\
\hline Q4 & -0.002999 & -0.000840 & 0.000688 & 0.000333 & 0.003621 & $0.006620^{* * *}$ & (2.04) \\
\hline $\mathrm{Q} 5(>0)$ & 0.000209 & 0.002564 & 0.003084 & 0.002206 & 0.004129 & $0.003920^{* * *}$ & (1.76) \\
\hline Q5-Q1 & $0.013248^{* *}$ & $0.004674^{* *}$ & $0.003812^{*}$ & $0.003540^{*}$ & $0.003163^{*}$ & & \\
\hline t-statistics & $(3.28)$ & $(2.17)$ & $(1.79)$ & $(1.84)$ & $(1.81)$ & & \\
\hline
\end{tabular}

Following Kaniel et al. (2008), we employ the previous 9 weeks to construct the five weekly NIT quintiles, where quintile 1 consists of stocks with more negative NIT which means further selling, and quintile 5 consists of stocks with further positive NIT which means more buying. In panel A, the method for return quintile is the same the way we put stocks into NIT quintiles (the most negative return quintile 1 and the most positive return quintile5). 25 portfolios are organized based on intersection of the five return quintiles and the five NIT quintiles, and we calculate market-adjusted returns for each portfolio in the week subsequent to the formation week. The last two rows of the panel show the payoffs to buying a portfolio with prior week high individual buying (NIT quintile 5) and selling portfolio with high individual selling (NIT quintile 1) in each return quintile. In panel B instead of previous returns we use previous turnover and NIT. We construct 25 portfolios similar to panel A. The last two columns show the payoff to the buying turnover (quintile 5) and selling turnover (quintile 1) strategies.

Panel B of Table 4 indicates that the information provided in the NIT measure is different from that in turnover, also future returns information from both of them are independent. The strategy which suggests buying the stocks in NIT quintile 5 and selling the stocks in NIT quintile 1 generates statistically significant payoffs in each turnover column. The strategy which suggests buying the stocks in turnover quintile 5 and selling the stocks in turnover quintile 1 generates payoffs which are statistically significant in each NIT row. The findings indicate that the informational content of turnover and NIT is different. Kaniel et al. (2008) argue that the possible reason is due to the non-linear relationship between NIT and returns. Because volume measure is an absolute value while net individual trading (NIT) is a directional one, the meaning of the non-linearity is significant volume.

To investigate net individual trading, turnover and past returns simultaneously, this study runs Fama and Macbeth (1973) regressions, where return in week $t+1$ are regressed on week $t$ returns, turnover, and NIT. In accordance to our method employed in section 2, we transform net individual trading into decile ranks (the NITDecile variable). In a similar manner, turnover is transformed into decile ranks because Gervais et al. and Kaniel et al. find volume transformation as a functional factor in returns prediction. Table 5 shows the results running regression models. The results of the univariate and also multivariate regressions indicate that coefficients on NITDecile are negative and on TurnoverDecile are significantly positive. The coefficient on past return is significantly positive, which is consistent with the results from the portfolio-sorting approach.

Our finding as the first establishment in TSE indicates about positive (negative) short-horizon abnormal returns after high buying (selling) by individuals that NIT has negative relationship with stock returns. Kaniel et al. (2008) argue that the relationship is because of immediacy required liquidity that is provided by the individuals for institutions. 
Table 5: Return Predictability: Trading Volume, NIT and Returns

\begin{tabular}{|c|c|c|c|c|}
\hline \multicolumn{5}{|c|}{ TSE Returns } \\
\hline Size Groups & $\begin{array}{c}\text { Intercept } \\
\text { (t-statistic) }\end{array}$ & $\begin{array}{l}\text { Return (t) } \\
\text { (t-statistic) }\end{array}$ & $\begin{array}{c}\text { NITDecile (t) } \\
\text { (t-statistic) }\end{array}$ & $\begin{array}{c}\text { TurnoverDecile (t) } \\
\text { (t-statistic) }\end{array}$ \\
\hline \multirow[t]{7}{*}{ All stocks } & $\begin{array}{l}0.0004 \\
(0.64)\end{array}$ & $\begin{array}{c}0.2533^{*} \\
(7.40)\end{array}$ & & \\
\hline & -0.0014 & & $-0.0039^{*}$ & \\
\hline & $(-1.12)$ & & $(-2.14)$ & \\
\hline & -0.0001 & & & $0.8917^{*}$ \\
\hline & $(-0.17)$ & & & $(2.51)$ \\
\hline & -0.0042 & $0.425^{*}$ & $-0.0612^{*}$ & $18.17^{*}$ \\
\hline & $(-0.85)$ & $(2.07)$ & $(-2.19)$ & $(2.65)$ \\
\hline \multirow[t]{8}{*}{ Small stocks } & 0.0012 & $0.3020^{*}$ & & \\
\hline & $(1.50)$ & $(6.44)$ & & \\
\hline & $-0.0034^{*}$ & & $-0.0143^{*}$ & \\
\hline & $(-1.65)$ & & $(-3.30)$ & \\
\hline & -0.0003 & & & $1.339^{*}$ \\
\hline & $(-0.29)$ & & & (1.93) \\
\hline & $-0.0063^{*}$ & $0.8017^{*}$ & $-0.0820^{*}$ & $6.2283^{*}$ \\
\hline & $(-1.81)$ & (1.93) & $(-1.73)$ & $(1.75)$ \\
\hline \multirow[t]{8}{*}{ Mid-cap stocks } & 0.00003 & $0.2347^{*}$ & & \\
\hline & $(0.05)$ & $(5.30)$ & & \\
\hline & -0.00103 & & $-0.0054^{*}$ & \\
\hline & $(-0.74)$ & & $(-1.84)$ & \\
\hline & -0.0012 & & & $2.2803^{*}$ \\
\hline & $(-1.16)$ & & & $(2.01)$ \\
\hline & -0.0001 & $0.2675^{*}$ & $-0.0717^{*}$ & $13.44^{*}$ \\
\hline & $(-0.05)$ & $(2.04)$ & $(-1.79)$ & $(2.18)$ \\
\hline \multirow[t]{8}{*}{ Large stocks } & -0.0005 & $0.1981^{*}$ & & \\
\hline & $(-0.47)$ & $(4.31)$ & & \\
\hline & $-0.0026^{*}$ & & $-0.0061^{*}$ & \\
\hline & $(-2.44)$ & & $(-1.90)$ & \\
\hline & -0.0008 & & & $3.027^{*}$ \\
\hline & $(-0.93)$ & & & $(2.21)$ \\
\hline & -0.0039 & $0.6750^{*}$ & $-0.0356^{*}$ & $3.133^{*}$ \\
\hline & $(-1.34)$ & $(1.86)$ & $(-1.87)$ & (1.89) \\
\hline
\end{tabular}

The dependent variable is Return $(\mathrm{t}+1)$, and the independent variables are Return $(\mathrm{t})$, NITDecile (t), and TurnoverDecile $(\mathrm{t})$. The TurnoverDecile variable is comparable to that in Gervais et al. (2001) and Kaniel et al. (2008). It categorizes the weekly turnover (number of traded stocks over the number of outstanding stocks) into 10 deciles, by comparing it to the same stock's turnover in the preceding 9 weeks. The NIT measure is explained in section 1. We measure the NITDecile variable similar to TurnoverDecile. We employ Fama-MacBeth to run the regression models: (1) a cross-section regression is run for each week in the sample period and (2) test statistics are based on the time series of the coefficient estimates. We present the mean coefficient of the weekly regression using the Newey-West correction for the standard errors to compute the t-statistics.

\section{CONCLUSIONS}

Our analysis of stock trading by individual investors on the TSE indicates four important findings. First of all, by considering the limited time series, the short-term trading behavior of individual investors can be explained on the basis of contrarian and return reversal strategy, which supports our argument that individual investors are liquidity providers for institutions. Second, we document that the information of NIT measures is different from that of turnover and each as an independent variable can predict future stock return. Third, there is a positive relationship between future return and turnover. Forth, we find that there is a negative relationship between the net individual trading and future short-horizon returns.

The first three of the results are similar to those of Kaniel et al. (2008). But the forth one is in contrast to Subrahmanyam (2005), that indicated net trade imbalances cannot predicts returns. It shows that the net order flow of individual investors may be better measure of the liquidity demand than the net trade imbalance of Subrahmanyam (2005). Also, the fourth result is contrary to Kaniel et al. (2008) who find that net individual trading 
is positively related to future short-horizon returns. As one of the reasons for this discrepancy we can refer to Kenth and Nofsinger (2003): stocks that are bought by individual investors to be a more negative abnormal return over the period, while stocks that are bought by institutions to be a more positive abnormal return over the period. In the end, to explain the positive relation between the future return and the current turnover we point out to Gyung et al. (2003). They argue that in emerging markets, turnover and the market returns are positively correlated, and since the Tehran Stock Exchange is placed in the emerging markets (Hu, 1997), therefore the result can be applied to the TSE.

\section{AUTHOR INFORMATION}

Dr. Abdollah Khani is an Assistant Professor in University of Isfahan. He holds a Ph.D. in accounting. He has published more than 30 papers in refereed research journals. His papers appear in journals such as Journal of Study of Accounting and Auditing, Accounting Research, Financial Accounting Research, Stock Journal and etc. His research area is Accounting, Auditing, Finance and Behavioral Finance. He was awarded as top scholar in 2012. Dr. Abdollah Khani, Accounting Department, University of Isfahan, Hezarjerib Street, Isfahan, Iran. E-mail: dr.a.khani@gmail.com

Dr. Ali Saeedi is a Senior Lecturer in the Taylor's Business School. He graduated with a Bachelor of Arts (Accounting) from Petroleum University of Technology, Iran. He obtained his Master Degree from Allameh Tabatabaee University and Ph.D. in Accounting from Tehran University, Iran. He has published more than 30 papers and 3 books. He has also supervised, advised, and examined more than 25 dissertations. His research area is Market Based Accounting Research, Financial Reporting, Corporate Governance, and Accounting Information Systems. Dr. Saeedi is a member of the Association of Iranian Certified Public Accountants (AICPA). Dr. Ali Saeedi (Corresponding author) Business School, Taylor's University, 47500 Subang Jaya, Selangor, Malaysia. E-mail: AliSaeedi.Velashani@taylors.edu.my (Corresponding author)

Asieh Khadem Khorasani has M.A. in Accounting from University of Esfahan. Her thesis awarded as the best thesis in 2012. Her research interest is the impact of Pattern Behavioral of Individual Investors on Stock Returns and Risk. Asieh Khadem Khorasani, (Master in Accounting), Accounting Department, University of Isfahan, Hezarjerib Street, Isfahan, Iran. E-mail: as.khadem@gmail.com

\section{REFERENCES}

1. Barber, B. M. \& Odean, T. (2000). Trading is Hazardous to Your Wealth: The Common Stock Investment Performance of Individual Investors. Journal of Finance, 55(2), 773-806.

2. Billmeier A. \& Isabella, M. (2008). What Drives Stock Market Development in Emerging Markets Institutions, Remittances, or Natural Resources? Journal of Emerging Markets Review, 10(1), 23-35.

3. Daniel, K., Hirshleifer, D. \& Subrahmanyam, A. (1998). Investor Psychology and Security Market Underand Overreactions. Journal of Finance, 53(6), 1839-1885.

4. DØskeland, T. M. \& Hvide, H. K. (2011). Do Individual Investors Have Asymmetric Information Based on Work Experience? Journal of Finance, 66(3), 1011-1041.

5. Fama, E. F. \& MacBeth, J. D. (1973). Risk, Return and Equilibrium: Empirical Tests. Journal of Political Economy, 81(3), 607-636.

6. Ferris, S. P., Haugen, R. A., Makhija, A. K. \& Harris, L. (1988). Discussion of Predicting Contemporary Volume with Historic Volume at Differential Price Levels: Evidence Supporting the Disposition Effect. Journal of Finance, 43(3), 698-699.

7. Gervais, S., Kaniel, R. \& Mingelgrin, D. H. (2001). The High-Volume Return Premium. Journal of Finance, 56(3), 877-919.

8. Goetzmann, W. N. \& Kumar, A. (2008). Equity Portfolio Diversification. Review of Finance, 12(3), 433463.

9. Griffin, J. M., Harris, J. H. \& Topaloglun, S. (2003). The Dynamics of Institutional and Individual Trading. Journal of Finance, 58(6), 2285-2320.

10. Grossman, S. J. \& Miller, M. H. (1988). Liquidity and Market Structure. Journal of Finance, 43(3), 617633. 
11. Hu, S. (1997). Trading Turnover and Expected Stock Returns: the Trading Frequency Hypothesis and Evidence from the Tokyo Stock Exchange. Working paper.

12. Jegadeesh, N. (1990). Evidence of Predictable Behavior of Security Returns. Journal of Finance, 45(30), 881-898.

13. Kaniel, R., Saar, G. \& Titman, S. (2008). Individual Investor Trading and Stock Returns. Journal of Finance, 63(1), 273-310.

14. Kenneth, A. K. \& Nofsinger, J. R. (2003). The Behavior and Performance of Individual Investors in Japan. Working paper.

15. Lakonishok, J. \& Smidt, S. (1986). Volume for Winners and Losers: Taxation and Other Motives for Stock Trading. Journal of Finance, 41(4), 951-974.

16. Lehmann, B. N. (1990). Fads, Martingales, and Market Efficiency. Journal of Economics, 105(1), 1-28.

17. Liu, Z. \& Spiegel, M. M. (2011). Boomer Retirement: Headwinds for US Equity Markets? FSBR Economic Letter, 26.

18. O'Neill, J., Wilson, D., Purushothaman, R. \& Stupnytska, A. (2005). How Solid Are the BRICs? Global Economics Paper 99, Vol. 134, New York: Goldman Sachs.

19. Odean, T. (1998). Are Investors Reluctant to Realize Their Losses? Journal of Finance, 53(5), 1775-1798.

20. Polkovnichenko, V. (2005). Household Portfolio Diversification: A Case for Rank-Dependent Preferences. Journal of Financial Studies, 18(4), 1467-1502.

21. Sang-Gyung, J., Marathe, A. \& Shawky, H. A. (2003). Liquidity and Stock Returns in Emerging Equity Markets. Journal of Emerging Markets Review, 4(1), 1-24.

22. Shefrin, H. \& Statman, M. (1985). The Disposition to Sell Winners Too Early and Ride Losers Too Long: Theory and Evidence. Journal of Finance, 40(3), 777-790.

23. Subrahmanyam, A. (2005). Distinguishing Between Rationales for Short-Horizon Predictability of Stock Returns. Journal of Financial Review, 40(1), 11-35. 